\title{
TEACHING THE IMPORTANCE OF INFORMATION, SUPPLY CHAIN MANAGEMENT, AND MODELING: THE SPREADSHEET BEER-LIKE GAME
}

\author{
Andrew A. Tiger, Southeastern Oklahoma State University, atiger@sosu.edu \\ Daniel C. Benco, Southeastern Oklahoma State University, dbenco@sosu.edu \\ Chandra Fogle, Southeastern Oklahoma State University, cfogle@sosu.edu
}

\begin{abstract}
This paper addresses a new teaching tool that reproduces aspects of the famous MIT beer game using spreadsheet modeling. In the traditional beer game, students learn that incomplete information leads to suboptimal decisions. In addition to this outcome, the spreadsheet beer-like game (SBG) addresses unplanned supply chain disruptions, and students learn about building decision support systems. The SBG only requires MS-Excel, possesses optimization capability, and uses open code to facilitate modification. A brief student survey demonstrates the potential benefits of the SBG. Sample applications are provided using optimization and how to design to minimize the disruptive impact of unplanned events such hurricanes or acts of terrorism.
\end{abstract}

Keywords: Beer Game, DSS, Spreadsheets, Simulation, Supply Chain Management

\section{INTRODUCTION}

Introduced in the 1960s by MIT, the traditional Beer Game (TBG) simulates a production and distribution system and is a teaching tool in operations management courses. In its original form, the game was played on a large board on which four locations represented the factory, the distributor, the wholesaler, and the retailer. Pennies represented inventory, and external demand was represented by a stack of cards. Four players (or groups) managed one of the four supply chain components, and each player's objective was to minimize the total holding and backorder costs borne by the component. An excellent summary of the mechanics of the TBG is presented by Simchi-Levi [18].

The main lessons to be learned by students playing the TBG were that incomplete information led to suboptimal decisions, and that demand as quantified by the next downstream supply chain component may or may not reflect ultimate customer demand. "Demand" at any of the four stages was represented only by the inventory needs of the next downstream component, and students usually overreacted (i.e., over- ordered).

For successful use, the TBG requires small class sizes. Since only four groups are allowed, class sizes over 12 limit the effectiveness of the TBG as a teaching tool. Additionally, the TBG offers little flexibility if game modifications are desired to teach other aspects of supply chain management. The computerized beer game (CBG) was developed to resolve the shortcomings of the TBG [18]. The CBG is a standalone computer application with options incorporated that allow for the inclusion of lead time reduction, global information sharing, and centralized management.

The beer game in both its traditional and computerized forms continues to be used as a supply chain management teaching tool $[4,6,7 \& 19]$.

Spreadsheets (particularly MS Excel) are also widely used as teaching tools in operations research/management science $[9,13-15 ; 20]$. This popularity is evidenced by the explosion of spreadsheet simulation modeling textbooks $[12,16$, 17, 21, 22]. Lavelle [14] contends that spreadsheet solutions force students to decompose problems into givens and require them to map out a method of analysis. Benco and Tiger [5] note that "built-in mathematical functions let the student focus on problem analysis rather than mundane numbercrunching... [and] this thought process is precisely what students need to learn so that, as employees, they can apply problem-solving skills in the workplace."

In 2003, AACSB reintroduced management science as an expected learning experience. Prior, in 1991, AACSB had eliminated this requirement; management science courses were viewed by many as irrelevant because they were being taught primarily as math courses. However, with the move towards spreadsheet modeling, interest in management science has led AACSB to reverse itself [8]. Essentially, the advent of technology created the renewed interest in management science, where the focus is on the decision-making process. Very 
recently, Heinrichs and McDonald [10] chaired a joint session of the Association of Business Information Systems (ABIS) and the Southwest Decision Science Institute (SWDSI) concerning IS enrollment and sustainability. Part of the discussion was the emphasis of technology in management science and the opportunity to combine them for success.

An extensive literature review revealed no evidence that anyone is using a combination of the beer game and spreadsheets as a single, integrated learning tool. The spreadsheet beer-like game (SBG), explained in the next section, extends both the TBG and the CBG by incorporating current operations management, information technology, and spreadsheet modeling using only the functions and formulae available in MS Excel to enhance the planning, modeling, and design skills of students.

\section{SBG}

In brief, the SBG offers students the following advantages:

- It addresses a wide variety of supply chain issues, including external demand; multi-echelon internal demand; variability in demand and lead time; inventory policies; and logistics, encompassing the movement of both material and information.

- It serves as a tool for system design for decision support systems. The student is not limited to playing the role of one element of the supply chain; rather, the student learns about problem solving through model building.

- MS-Excel is the only software required to use the SBG.

- Optimization is available, and students can engage in sensitivity analysis by changing the values of certain cells in trial-and-error exercises.

- Its open code makes it easy for the student to expand or modify the SBG. Complex bills of material, service level vs. cost issues, and increases in scope are achievable.

The SBG is not without its limitations. The SBG stresses individual effort rather than group play and may not be well suited in contexts that mimic the environment in which the game was originally designed.

As a teaching tool, the SBG is still in its infancy. However, it has been used in both management science courses to teach modeling and operations management courses to teach supply chain management. Table 1 supports its potential teaching effectiveness.

Table 1. Student Survey Results

\begin{tabular}{|c|c|c|c|}
\hline $\begin{array}{l}\text { After using the SBG, } \\
\text { I have a better } \\
\text { understanding of }\end{array}$ & Mean & SD & $\begin{array}{c}\text { No. of } \\
\text { Negative } \\
\text { Responses }\end{array}$ \\
\hline $\begin{array}{l}\text {... spreadsheet } \\
\text { functionality. }\end{array}$ & 1.11 & .94 & 2 \\
\hline ... simulation. & 1.37 & .76 & 0 \\
\hline $\begin{array}{l}\text {... supply chain } \\
\text { management. }\end{array}$ & 1.11 & 1.10 & 2 \\
\hline ... optimization. & .95 & 1.27 & 3 \\
\hline $\begin{array}{l}\ldots \text { decision support } \\
\text { systems. }\end{array}$ & 1.05 & 1.35 & 2 \\
\hline
\end{tabular}

7 point scale: -3 strongly disagree to +3 strongly agree $(\mathrm{n}=20)$

\section{MODEL DESCRIPTION}

This section provides an overview of the SBG. To request a copy of the SBG, contact the first author at atiger@sosu.edu. The SBG does not require any additional software; however, it does lend itself to optimization add-ins for system design. Screen snapshots are used as references when describing the model (to copy the screen, hold the Control key down while pressing the Print Screen key). Screen snapshots have been very successful for the authors when teaching spreadsheet programming through distance learning courses.

The SBG spreadsheet has seven worksheets. Table 2 summarizes each worksheet's primary purpose. No Visual Basic modules or code exists. All modeling is performed using cell formulae. However, Visual Basic is an excellent tool for adding additional analytical capabilities to spreadsheets. 
Table 2. Worksheet Descriptions

\begin{tabular}{ll}
\hline Worksheet Name & Description \\
\hline WELCOME & $\begin{array}{l}\text { Provides the basic design } \\
\text { and rules. }\end{array}$
\end{tabular}

INPUTS_OUTPUTS Input model parameters and display the cost and service summary values.

CHARTS Displays charts of inventory, service and cost.

RETAILER Holds the logic for the Retailer, the supply chain location with direct contact with the external customer.

WHOLESALER Holds the logic for the Wholesaler.

DISTRIBUTOR Holds the logic for the Distributor.

FACTORY

Holds the logic for the

\section{The WELCOME Worksheet}

Figure 1 shows the WELCOME worksheet. This worksheet provides a basic understanding of the SBG, including a figure showing the supply chain design, as well as material and information flows. Factory, the supply chain location farthest upstream.

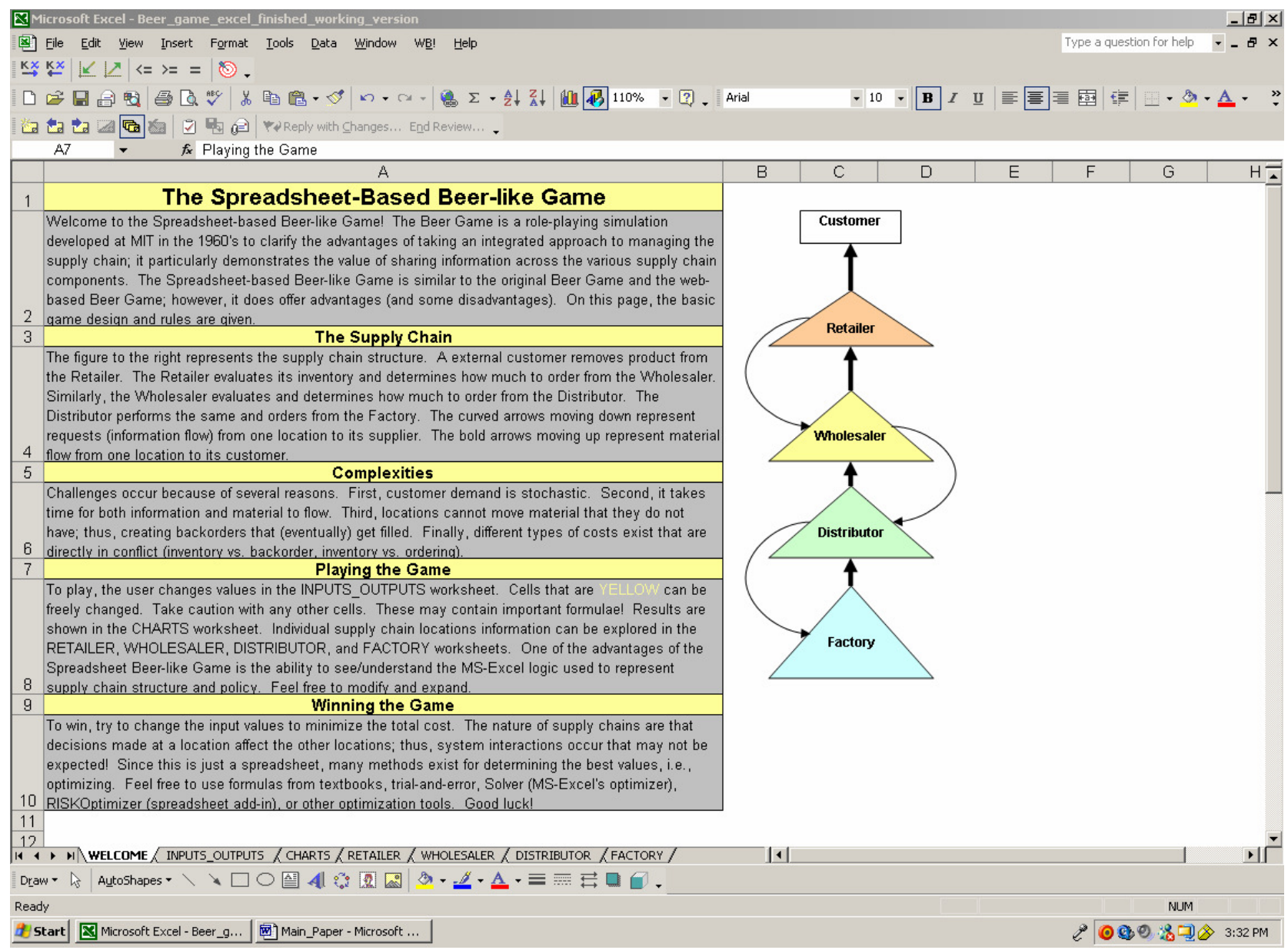

Figure 1. WELCOME Worksheet for the Spreadsheet Beer-like Game 


\section{The INPUTS_OUTPUTS Worksheet}

The next worksheet, INPUTS_OUTPUTS, is the primary location for changing system required values and seeing summary results. For each location, four types of costs can be modeled: shortage cost per unit, holding cost per unit, ordering cost per order, and purchase cost per unit.

The next set of inputs is the set of supply chain parameters of inventory and lead times. For this teaching tool, only the $(\mathrm{s}, \mathrm{S})$ replenishment policy is modeled. Since the SBG code is open and only uses MS Excel, other policies can be modeled if desired.
The last set of inputs is the set defining external customer demand for the Retailer. For this teaching tool, randomly generated demand is from a normal distribution rounded to the nearest integer. Functionality exists for modeling other demand patterns.

\section{The CHARTS Worksheet}

The next worksheet, CHARTS, provides results. See Figure 2. Results include costs, service levels and inventory profiles that are location specific. Service levels are the percentage of weekly-specific material requested that is satisfied in that week.

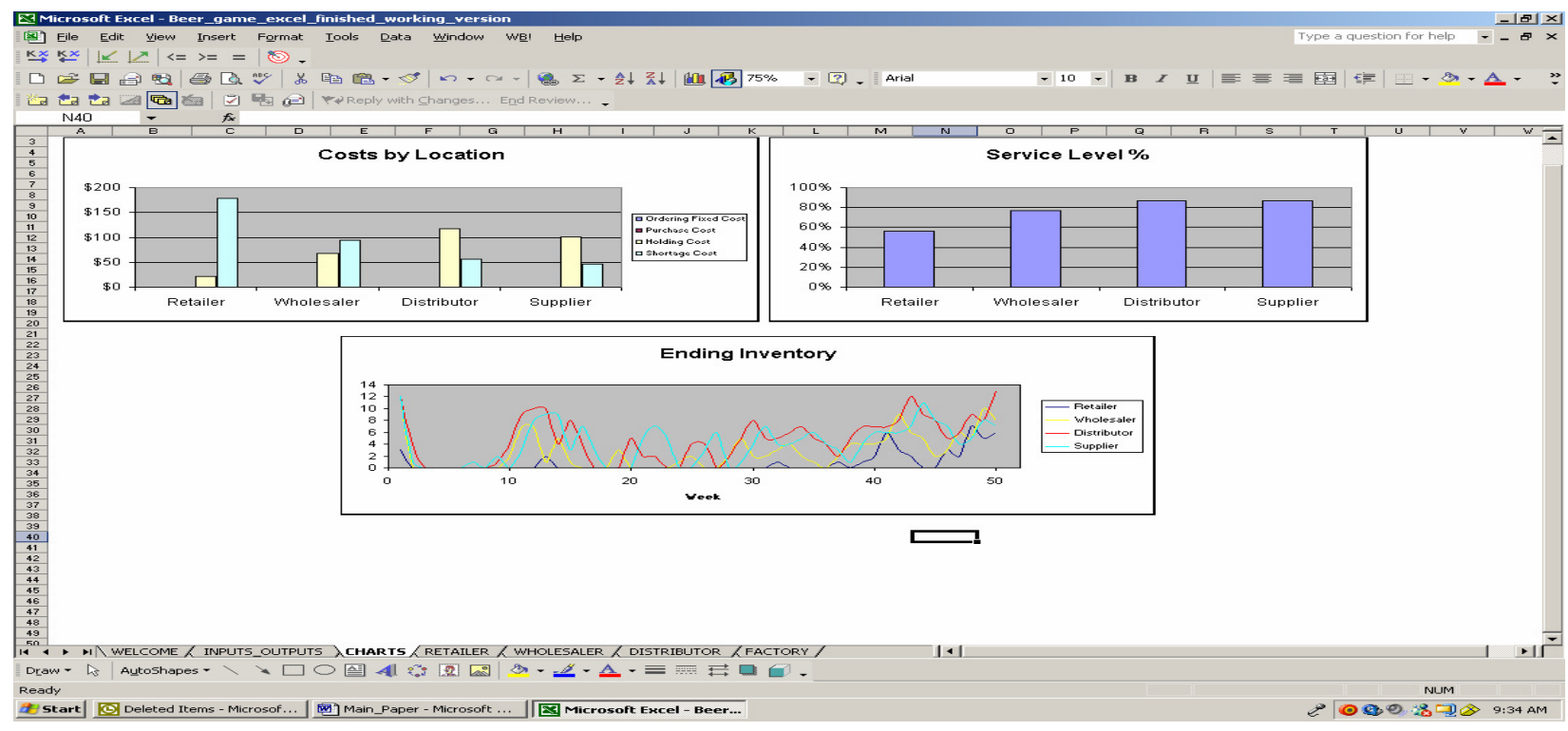

Figure 2. CHARTS Worksheet for the Spreadsheet Beer-like Game

\section{The RETAILER, WHOLESALER, DISTRIBUTOR and FACTORY Worksheets}

The final four worksheets represent the four locations in the supply chain. With minor exceptions, all use similar logic and MS-Excel functions to represent the supply chain material and information flow. The MS-Excel functions used are the if(), offset(), round(), norminv(), rand() and $\max ()$ functions. Many excellent MS Excel texts exist for elaborating on these and other MS Excel functions. Figure 3 provides a partial screen snapshot for the RETAILER worksheet. 


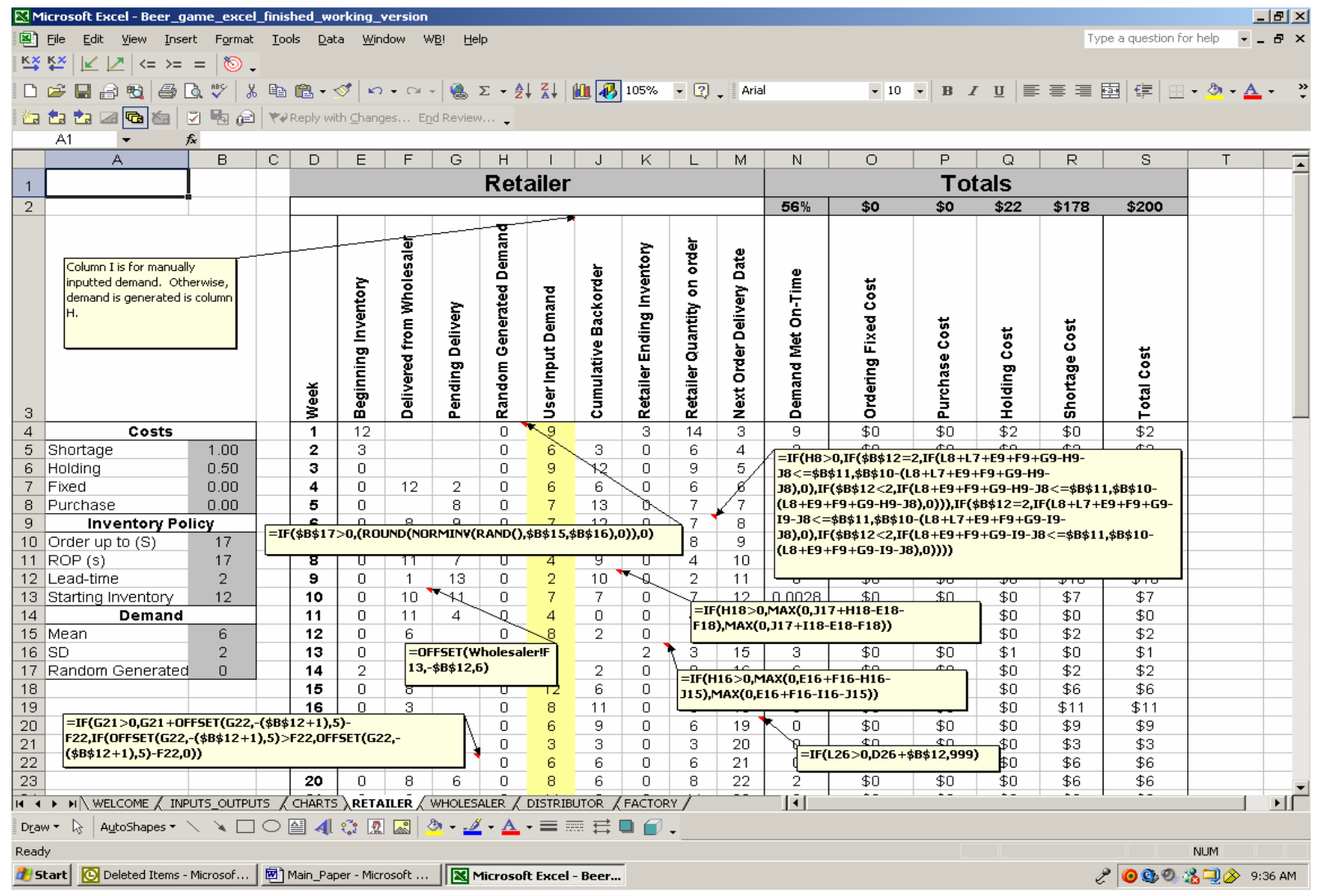

Figure 3. RETAILER Worksheet for the Spreadsheet Beer-like Game

\section{TEACHING APPLICATIONS \\ USING SOLVER TO OPTIMIZE THE INVENTORY POLICY}

A relevant application for teaching supply chain management is determining the optimal order policy using spreadsheet optimization. Once the SBG's model design is presented and the impact of changing inventory parameters is explored using a trial-anderror approach of changing cell values, the next step is to determine the best values. Even with a sophisticated trial-and-error approach, students will realize that finding the best values is a lengthy process and will appreciate having optimization capability directly within MS-Excel. Therefore, MSExcel's Solver is used to demonstrate spreadsheet optimization. Other add-ins are available and may be more powerful; however, Solver is part of MS-Excel and always available.

\section{STUDYING THE IMPACT OF SUPPLY CHAIN DISRUPTIONS ON PERFORMANCE}

A particularly relevant supply chain management challenge is how to design a supply chain that is robust to unplanned supply chain disruptions. Major events such as work force stoppages, plant accidents, weather catastrophes, terrorist threats/acts and governmental policy often cause temporary, but fundamental, changes in sourcing decisions. The literature addresses unplanned events $(1-3,11)$; however, no evidence of a teaching tool exists. The SBG has built-in functionality to model unplanned downtime and offers students the chance to plan and design based on this possibility.

\section{CONCLUSIONS}

In alignment with the IACIS theme of the changing role of IS education, and as a direct action supporting AACSB's emphasis on management science as an expected learning experience, this paper 
presents a new spreadsheet-based teaching tool using MIT's Beer Game as its basis. The SBG offers a range of opportunities. First, students can learn about the logistics of supply chain management and about the value of complete information. Second, instructors can use the tool as both a supply chain management learning device and a decision support system learning device. Finally, businesses can adapt the SBG to their own real-world scenarios with the goal of improving supply chain management under a variety of real-world contexts: incomplete information, varying lead times, and planned and unplanned disruptions to the regular flows of information and inventory being modeled.

\section{REFERENCES}

1. Anonymous (2004). The "Oops!" factor. Logistics Today, 45(5), 46-47.

2. Asgekar, V. (2003). Event management graduates with distinction. Supply Chain Management Review, 7(5), 15.

3. Attaran, M. (2004). Nurturing the Supply Chain. Industrial Management, 46 (5), 15-20.

4. Bean, M. (2005). Bullwhips and beer: Why supply chain management is so difficult. Forio Business Simulations. Available online at http://www.forio.com/nearbeer.htm.

5. Benco, D., \& Tiger, A. (2004). Using spreadsheet-based math modeling in small business and independent consulting. Proceedings of the USASBE Conference, Dallas.

6. Coakley, J. R., Drexler, J. A., Larson, E. W. \& Kircher, A. E. (1998). Using a computer-based version of the beer game: Lessons learned. Journal of Management Education, 22(3), 416424.

7. Goodwin, J. S., \& Franklin, Sr., S. G. (1994). The beer distribution game: Using simulation to teach system concepts. The Journal of Management Development, 8(7), 7-15.

8. Grossman, T. (2003). Getting down to business. ORMS Today, 30(4), 18-21.

9. Grossman, T. A., Jr. (1999). Teachers' forum: Spreadsheet modeling and simulation improves understanding of queues. Interfaces, $29 \backslash(3)$, 88103.
10. Heinrichs, L. R. \& McDonald, J. (2006). The state of IS enrollments: Have we turned the corner?, Proceedings of the 2006 SWDSI Conference, Oklahoma City.

11. Hoffman, W. (2005). When supply chains shatter. Traffic World, (June 27), 1.

12. Jackson, M. \& Staunton, M. (2002). Advanced Modeling in Finance Using Excel and VBA.. New York, NY: John Wiley \& Sons.

13. Johnson, D. J. (2002). A spreadsheet method for calculating work completion time probability distributions of paced or linked assembly lines. International Journal of Production Research, 50(5), 1131-1153.

14. Lavelle, J. P. (1996). Enhancing engineering economy concepts with computer spreadsheets. The Engineering Economist, 41(4), 381-386.

15. Liberatore, M. J. \& Nydick, R. L. (1999). The teachers' forum: Breaking the mold-A new approach to teaching the first MBA course in management science. Interfaces, 29(4), 99-116.

16. Ragsdale, C. T. (2004). Spreadsheet Modeling and Decision Analysis. Mason, $\mathrm{OH}$ : Thomson South-Western.

17. Shafer, S. M. \& Meredith, J. R. (1998). Operations Management: A Process Approach with Spreadsheets. New York, NY: John Wiley \& Sons.

18. Simchi-Levi, Kaminsky, D., P. \& Simchi-Levi, E. (2003). Designing and Managing the Supply Chain: Concepts Strategies \& Case Studies. New York, NY: McGraw-Hill Irwin.

19. Sparling, D. (2002). Simulations and supply chains: Strategies for teaching supply chain management. Supply Chain Management, 7(5), 334-342.

20. Winston, W. L. (1996). The Teachers' forum: Management science with spreadsheets for MBAs at Indiana University. Interfaces, 26(2), 105-111.

21. Winston, W. L. (2001). Simulation Modeling Using @ Risk. Pacific Grove, CA: Duxbury.

22. Winston, W. L. \& Albright, S. C. (2000). Practical Management Science. Pacific Grove, CA: Duxbury. 